\title{
ESTIMATING THE LABOR MARKET SIGNALING VALUE OF THE GED*
}

\author{
J OHN H. TYLER \\ RICHARD J. MURNANE \\ J OHN B. WILLETT
}

This paper tests the labor market signaling hypothesis for the General Educational Development (GED) equivalency credential. Using a unique data set containing GED test scores and Social Security Administration (SSA) earnings data, we exploit variation in GED status generated by differential state GED passing standards to identify the signaling value of the GED, net of human capital effects. Our results indicate that the GED signal increases the earnings of young white dropouts by 10 to 19 percent. We find no statistically significant effects for minority dropouts.

The positive correlation between education and earnings is one of the consistent findings of the human capital literature. In the early 1970s, however, Arrow [1973] and Spence [1973] formulated an alternative, information-based explanation for the education-earnings relationship. Over the last 25 years many economists have conducted empirical work aimed at exploring the signaling hypothesis. It has proved difficult, however, to distinguish between human capital and signaling explanations of the observed relationship between education and earnings. ${ }^{1}$

* We are especially grateful to J effrey Kling, J oshua Angrist, Lawrence Katz, and Caroline Minter Hoxby for helpful comments. We owe thanks to J anet Baldwin of the GED Testing Service of the American Council on Education, Linda Headley Walker of the State E ducation Department of New York, LeslieAverna of the Connecticut Department of Education, and J ohn Sojat of the Florida Department of Education for their assistance in providing data on GED testers, and to personnel of the Office of Research and Statistics at the Social Security Administration's Baltimore Headquarters, particularly Peter Wheeler and Russell Hudson, for providing and assisting with Social Security earnings data. The support of these individuals and organizations does not imply their endorsement of the contents of this paper.

We gratefully acknowledge the support provided by the National Center for the Study of Adult Learning and Literacy (NCSALL) and the Rockefeller, Russell Sage, Spencer, and Smith Richardson Foundations. Work supported by NCSALL was supported under the Educational Research and Development Centers Program, Award Number R309B60002, as administered by the Office of Educational Research and I mprovement/N ational I nstitute on Postsecondary E ducation, Libraries, and Lifel ong Learning, United States Department of Education. The contents do not necessarily represent the positions or policies of the National Institute on Postsecondary Education, Libraries, and Lifelong Learning, the Office of Educational Research and I mprovement, or the U nited States Department of Education, and you should not assume endorsement by the Federal Government.

1. For recent attempts see Lang and Kropp [1986], J aeger and Page [1994], and Park [1994].

๑ 2000 by the President and Fellows of Harvard College and the Massachusetts Institute of Technol ogy.

TheQuarterlyJ ournal of Economics, May 2000 
Ideal data for identifying the returns to a signal would contain exogenous variation in signaling status among individuals with similar levels of human capital. In this paper we approximate that ideal in estimating the returns to a particular labor market signal, the General Educational Development (GED) credential, and in so doing we provide a test of the signaling hypothesis for this credential.

The GED was introduced in 1942 to provide a way for veterans without a high school diploma to earn a secondary school credential. The GED program has evolved markedly so that today the credential is the primary "second chance" route to high school certification for school dropouts in the United States. Each year more than one million young people drop out of school, and eventually about one-third of them will acquire a GED.

Using interstate variation in GED passing standards, we are able to compare individuals who all chose to try to obtain a GED and who have the same GED test scores, but who differ in GED status because of differences in the stringency of the passing standards in their state of residence. We will argue that this "natural experiment" research design allows us to net out the effect of human capital on earnings, leaving clear estimates of the signaling value of the GED credential in the labor market.

Our estimates indicate that for young white dropouts who are on the margin of passing the GED exams, the signaling value of the GED increases annual earnings by 10 and 19 percent. We do not find statistically discernible returns to the GED signal for young minority dropouts, a puzzle we discuss later in the paper. ${ }^{2}$

In the next two sections we discuss the GED credential and our identification strategy. We then present our data, methods, and results. The paper closes with an extensive discussion of the potential threats to our identification strategy, an interpretation of our results, and a summary.

\section{The GED in the Labor Market and in the Literature}

The five tests in the GED battery cover mathematics, writing, social studies, science, and "interpreting literature and the arts."

2. Because of data limitations we are only able to identify individuals in our data as being members of one of two racial/ethnic groups: (1) white, non-Hispanics and (2) everyone else. The latter group includes African-Americans, Hispanics, and other minority group members. For expository clarity we refer to the two groups as "whites" and "minorities" in this paper. 
The writing component of the test includes an essay, and the rest of the battery consists of multiple choice questions. In the years relevant for this paper, the GED Testing Service (GEDTS) established a minimum passing standard that required a minimum score of at least 40 or a mean score of at least 45 over the five tests in the battery. However, the GED program is jointly supervised by the GEDTS and the state education agencies, and each state is free to set standards higher than the GEDTS minimum. Most states do so, creating the sources of variation critical to our study.

In 1996 a record 758,500 dropouts attempted the GED exams, and half a million were awarded the certificate. Table I illustrates the trends behind that record number. Based on October CPS data, the first row of Table I shows that the high school completion rate for 18-24 year-olds trended upward slightly from 1975 through 1992, and has been relatively steady through 1996. Beginning in 1988 the October CPS allows determination of

TABLE I

High School Completion Rates of 18-24 Year-Olds from 1975-1996, AND by METHOD OF COMPLETION FROM 1988-1996

\begin{tabular}{|c|c|c|c|c|c|c|c|c|c|c|c|c|}
\hline \multirow{2}{*}{$\begin{array}{c}\text { Completion } \\
\text { method }\end{array}$} & \multicolumn{12}{|c|}{ Yeara,b } \\
\hline & 1975 & 1980 & 1985 & 1988 & 1989 & 1990 & 1991 & 1992 & 1993 & 1994 & 1995 & 1996 \\
\hline \multicolumn{13}{|l|}{ Total } \\
\hline Completed & 83.6 & 83.9 & 85.4 & 84.5 & 84.7 & 85.6 & 84.9 & 86.4 & 86.2 & 85.8 & 85.3 & 86.2 \\
\hline Diploma & & & & 80.3 & 80.5 & 80.6 & 80.7 & 81.2 & 81.2 & 78.8 & 77.5 & 76.5 \\
\hline Alternative $e^{c}$ & & & & 4.2 & 4.2 & 4.9 & 4.2 & 5.2 & 4.9 & 7.0 & 7.7 & 9.8 \\
\hline \multicolumn{13}{|c|}{ White, non-Hispanic } \\
\hline Completed & 87.2 & 87.5 & 88.2 & 88.7 & 89.0 & 89.6 & 89.4 & 90.7 & 90.1 & 90.7 & 89.8 & 91.5 \\
\hline Diploma & & & & 84.4 & 85.1 & 84.8 & 85.2 & 85.7 & 85.5 & 84.2 & 82.6 & 81.0 \\
\hline Alternative & & & & 4.2 & 3.9 & 4.8 & 4.2 & 5.0 & 4.7 & 6.4 & 7.2 & 10.5 \\
\hline \multicolumn{13}{|c|}{ Black, non-Hispanic } \\
\hline Completed & 70.2 & 75.2 & 81.0 & 80.9 & 81.9 & 83.2 & 82.5 & 82.0 & 81.9 & 83.3 & 84.5 & 83.0 \\
\hline Diploma & & & & 76.1 & 76.9 & 77.9 & 77.3 & 75.9 & 76.1 & 75.2 & 75.4 & 73.0 \\
\hline Alternative & & & & 4.8 & 5.0 & 5.3 & 5.2 & 6.1 & 5.8 & 8.1 & 9.0 & 10.0 \\
\hline \multicolumn{13}{|l|}{ Hispanic } \\
\hline Completed & 62.2 & 57.1 & 66.6 & 58.2 & 59.4 & 59.1 & 56.5 & 62.1 & 64.4 & 61.8 & 62.8 & 61.9 \\
\hline Diploma & & & & 54.4 & 54.8 & 54.8 & 53.4 & 56.6 & 58.2 & 54.2 & 54.0 & 55.2 \\
\hline Alternative & & & & 3.8 & 4.7 & 4.2 & 3.1 & 5.5 & 6.1 & 7.6 & 8.8 & 6.7 \\
\hline
\end{tabular}

Source: Tables 13 and A25 in Dropout Rates in the United States: 1997, U. S. Department of Education, Office of Educational Research and I mprovement.

a. The numbers for the years 1992-1997 reflect new wording of the educational attainment items in the

b. The numbers for the years 1994-1997 reflect changes in the CPS due to newly instituted computerassisted interviewing and the change in the population controls to the 1990 Census-based estimates, with adjustment for the undercount in the 1990 Census.

c. Completed high school by means of an equivalency test such as a GED exam. 
whether high school "completion" culminated in a regular diploma or an alternative certification, and the GED is by far the most common alternative form of certification [Cameron and Heckman 1993]. The second and third rows of Table I show that the steady school completion rate over the 1990s masks opposite moving trends: completion via a regular high school diploma trended downward, while completion via GED certification trended upward. The last three panels of the table show that these trends were true for all racial/ethnic groups.

In general, GED holders are a relatively advantaged group compared with uncredentialed dropouts. On average they complete more years of schooling before dropping out, they have higher levels of measured cognitive skills, and their parents have more education. Even after controlling for these relative advantages, however, there are reasons to believe that GED holders might fare better in the labor market than dropouts without the credential.

First, for dropouts with low levels of basic cognitive skills or with English language deficiencies, raising skills to levels required to pass the GED battery may require considerable work resulting in increased human capital. While Cameron and Heckman [1993] report a median study time for the GED of only about twenty hours, the wording in the survey question on which their estimates are based could lead to an underestimation of the total GED preparation time. For example, it is not clear whether dropouts who required participation in English as a Second Language (ESL) or Adult Basic Education (ABE) courses prior to GED preparation would count the time spent in those classes as GED preparation on the survey question. Also, there is a long right-hand tail to this distribution so that the least skilled GED-holders may spend considerable time preparing to pass the tests. Thus, the amount of human capital associated with acquiring a GED, especially for low skilled dropouts, is still unclear. ${ }^{3}$

Returns to a GED can also be explained by a signaling hypothesis. Assuming a distribution of underlying productivity in the pool of dropouts, the more productive dropouts would like to signal their higher productivity to employers and receive a higher

3. In addition to human capital returns related to test preparation, there may be an additional human capital payoff from increased access to postsecondary education and training associated with GED acquisition. I $n$ a later section we will show that any human capital effects resulting from this route are likely to be very small for the dropouts who drive our results. 
wage offer. The GED credential may serve as this signal in the labor market. If the costs of acquiring the GED and the wage offers based on GED status are such that the expected net benefits of GED acquisition are negative for the less productive dropouts and positive for the more productive dropouts, then we could observe a separating equilibrium where GED acquisition is positively correlated with productivity and wages. ${ }^{4}$

Since the returns to a GED can be explained by either human capital or signaling theory, the empirical task is to estimate the signaling value of the credential net of any human capital effects associated with GED acquisition. A first step is establishing the correlations between GED acquisition and labor market outcomes.

Table II presents estimates from log earnings regressions using High School and Beyond data on individuals who were sophomores in 1980. The dependent variable is the log of average 1990-1991 earnings, years when most of the sample would have been $25-26$ years of age.

Across all of the models, regular high school graduates consistently show large advantages over dropouts, regardless of race/ethnicity. In the model s in col umns 1 and 2 that do not control for sophomore test scores, GED-holders have earnings that are about 16 percent higher than uncredentialed dropouts-well estimated for white dropouts and less well estimated for minority dropouts. Adding test score controls in the third and fourth columns, however, reduces the estimated GED effect for both whites and minorities so that neither estimate is statistically significant.

Since the positive but statistically insignificant estimates of the "GED effect" pick up both human capital and labor market signaling effect on earnings, one interpretation of these estimates is that any signaling effect of the GED is very small. However, a second interpretation we favor is that these baseline equations are misspecified because they do not allow the effect of the GED on earnings to vary according to the skill level of the dropout. This is important in interpreting our main results, since our estimates are based only on very low skilled GED-holders. We return to this subject later.

4. The actual pecuniary costs associated with GED acquisition are generally low, ranging from zero dollars in some states to around $\$ 50$ in other states. Thus, the binding costs for low productivity dropouts are more likely associated with opportunity costs tied tolong preparation time in upgrading skills or in the psychic costs associated with the school-like preparation for and taking of the seven and three-quarter hour battery of tests. 
TABLE II

Earnings Regressions for Individuals in the High School and Beyond Survey (Dependent Variable Is the Log of the Average of 1990-1991 Annual Earnings and Standard ERrors are in Parentheses.)

\begin{tabular}{lcccc}
\hline \hline & Whites $^{\mathrm{a}}$ & Minorities $^{\mathrm{b}}$ & Whites & Minorities \\
\hline Intercept & $9.518^{* *}$ & $9.320^{* *}$ & $9.455^{* *}$ & $9.199^{* *}$ \\
& $(0.057)$ & $(0.079)$ & $(0.059)$ & $(0.081)$ \\
Female & $-0.397^{* *}$ & $-0.306^{* *}$ & $-0.40^{* *}$ & $-0.298^{* *}$ \\
& $(0.019)$ & $(0.030)$ & $(0.022)$ & $(0.032)$ \\
GED & $0.162^{*}$ & 0.164 & 0.094 & 0.083 \\
& $(0.072)$ & $(0.109)$ & $(0.072)$ & $(0.109)$ \\
High school graduate & $0.536^{* *}$ & $0.581^{* *}$ & $0.380^{* *}$ & $0.400^{* *}$ \\
& $(0.057)$ & $(0.073)$ & $(0.059)$ & $(0.075)$ \\
Math test score & & & $0.012^{* *}$ & $0.008^{* *}$ \\
& & & $(0.002)$ & $(0.002)$ \\
Reading test score & & & 0.0002 & 0.002 \\
& & & $(0.003)$ & $(0.005)$ \\
Writing test score & & & 0.002 & $0.008^{\sim}$ \\
& & & $(0.003)$ & $(0.005)$ \\
Science test score & & & $-0.008^{*}$ & 0.003 \\
& & & $(0.004)$ & $(0.005)$ \\
Vocabulary test score & & & $0.007^{*}$ & $0.009^{*}$ \\
& & & $(0.003)$ & $(0.004)$ \\
Region dummies & & & Yes & Yes \\
$\mathrm{R}^{2}$ & Yes & 0.087 & 0.133 & 0.131 \\
$\mathrm{~N}^{\mathrm{d}}$ & 0.11 & 2,810 & 5,403 & 2,810 \\
\hline \hline
\end{tabular}

a. White, non-Hispanic.

b. Everyone not white, non-Hispanic

c. The regions are South, West, North Central, and Northeast.

d. Included in the sample were all dropouts (those with and without a GED as of the 1992 survey) and individuals with at least a high school degree who were interviewed in the 1992 HSB survey, who were not in the military in 1992 and not in college in both 1990 and 1991, who did not have zero earnings in both 1990 and 1991, and who had nonmissing values for their 1980 sophomore test scores.

In a widely cited study, Cameron and Heckman [1993] used data from the National Longitudinal Survey of Youth (NLSY) to show that male conventional high school graduates consistently outperform male GED-holders in the labor market. Their work, however, is less definitive on the question of how GED-holders fare relative to uncredentialed dropouts. They find that male GED-hol ders have wages that are between 3 and 6 percent higher than uncredentialed male dropouts, but the results are not statistically significant. They conclude that “. . .GED recipients lie between [uncredentialed] dropouts and [regular high school] graduates in their economic standing, but are much closer to dropouts" [Cameron and Heckman 1993]. 
While informative, their comparisons between uncredentialed dropouts and GED-holders are potentially problematic for two reasons. First, data limitations required that all uncredentialed dropouts in the data-both those who chose not to acquire a GED and those who attempted to acquire a GED but failed the exams-form the comparison group in their study. It is questionable whether either of these dropout groups provides a satisfactory counterfactual.

Constraints imposed by model specification, however, are potentially the most important and interesting reason to reexamine the returns to the GED. Similar to the specifications used in Table II, all of the Cameron and Heckman models constrain any GED effect on wages or employment to be the same for all dropouts, regardless of the skills they possess. Models that do not allow for a differential effect of the GED by skill may miss important elements of the way the GED works in the labor market. This may bean especially important consi deration regarding a signaling hypothesis. For example, it may bethat the GED is a more important signal for dropouts who leave school with low skills than for those wholeave school with higher skill levels.

As a result of our identification strategy, our estimates identify the signaling effect of the GED only for those dropouts on the margin of passing the GED exams-that is, for the very least skilled GED holders. If the returns to a GED arelarger for this Iow skilled population than for more highly skilled dropouts, then our results are potentially consistent with those of Cameron and Heckman.

\section{Estimating the Signaling Value of the Ged, Using Differential State Ged Passing Standards}

In this paper we take advantage of interstate variation in GED passing standards to generate variation in GED status among individuals with the same observed levels of human capital. Our identification strategy is simple. Given two sets of states, one with a lower GED passing standard than the other, we compare individuals with marginally passing GED test scores in the lower passing standard states with individuals who have the same GED test scores in the higher standard states. However, because of the morestringent GED passing standard, our comparison individuals in the higher passing standard states will not have the credential. Once we have accounted for differences in 
state labor markets, we can estimate the impact of the GED on earnings by comparing the mean earnings of the two groups. Since these individuals have the same GED test scores, any human capital effect on earnings captured by the GED test scores is removed from the estimates. There may be other forms of unobservable human capital differences between the two groups that would bias our estimates. We address the most obvious and problematic of these in a later section in the paper and conclude that they do not pose serious problems for the main estimates in this paper. Thus, we interpret the estimates from this methodology as the signaling effects of the GED on the earnings of dropouts who would choose to obtain the GED and are at the margin of passing. 5

Our data contain information on 1990 GED candidates from 45 states. All of the states in our sample define their GED passing standards by a combination of the minimum test score and the mean score over the five tests. In our research we are able to use three of the possible seven different passing standards that existed across the nation in 1990. They are, in ascending order of difficulty:

- a minimum score of at least 40 or a mean score of at least 45 ,

- a minimum score of at least 35 and a mean score of at least 45, and

- a minimum score of at least 40 and a mean score of at least 45.

The nature of our data, in combination with the standards above, dictate that we use minimum-mean score combinations to construct different GED score groups. The score groups were constructed so that, based on score group and state in which the GED was attempted, we can be assured of GED status. Thus, we constructed ten GED "score groups" based on the intersection of the minimum and mean score ranges represented in the rows and columns of Table III.

In Table III individuals in score groups 1 and 2 would have GED scores below the passing standard in any state in 1990. Individuals in score group 5 or higher would have scores above the passing standard of any state in our data in 1990. It is only in score groups 3 and 4-the "affected score groups"- that we find 
TABLE III

Ged Score Groups Formed by Combining Minimum and Mean Scores (Outlined Cells = Variation in Ged-Status by State, Dark Shading = All Possess Ged, No Shading = None Have GED.)

\begin{tabular}{ccc}
\hline \hline & \multicolumn{2}{c}{ Mean score } \\
\cline { 2 - 3 } Minimum score & $<45$ & $>=45$ \\
\hline $20-34$ & Score group 1 & \\
$35-39$ & Score group 2 & Score group 4 \\
$40-44$ & Score group 3 & Score group 5 \\
$45-46$ & & Score group 6 \\
$47-48$ & & Score group 7 \\
$49-50$ & & Score group 8 \\
$51-52$ & & Score group 9 \\
$53+$ & & Score group 10 \\
\hline \hline
\end{tabular}

variation in GED status by the state where the GED exams were taken in 1990. In each of these two scoring ranges individuals in states with the lower passing standard - the "treatment states"have a GED, while individuals in "comparison states" do not, due to higher passing standards.

Thus, we have these three natural experiments to test the signaling hypothesis as it pertains to the GED. We denote these experiments by the affected score group in each experiment.

-Experiment 4, where variation in GED status by state is in score group 4, the treatment states are those states that award a GED in score groups 4 and higher, and the comparison states are those that award a GED in score groups 5 and higher.

-Experiment 3, where variation in GED status by state is in score group 3, the treatment states are those states that award a GED in score groups 3 and higher, and the comparison states are those that award a GED in score groups 5 and higher.

-Experiment 3*, where variation in GED status by state is in score group 3, the treatment states are those states that award a GED in score groups 3 and higher, and the comparison states are those that award a GED in score groups 4 and higher.

Since the GED passing standards are set by the individual state education departments, and since these agencies are embedded in the state political system, the interstate variation in passing standards on which we rely is not transparently exogogenous. The fact that GED passing standards in general, and the ones we exploit in particular, have been relatively stable over time, 
however, suggests that states do not set the GED passing standard based on current state economic conditions. ${ }^{6}$ We assume that the variation in passing standards we use is exogenous conditional upon statefixed effects.

\section{Research Design}

\section{A. Data}

To exploit the sources of GED signaling status described above, we needed information on demographic characteristics, GED test-scores, state in which tested, and earnings for a sample of dropouts. The first three types of information came from administrative records of the GED Testing Service and the state education agencies of New York, Florida, and Connecticut. ${ }^{7}$ In the data from New York, Florida, and Connecticut, we have information on the universe of dropouts aged 16-21 who last attempted the GED tests in 1990. For data obtained from the GED Testing Service, we have, from each of 42 states, a sample of dropouts who were aged 16-21 when they attempted the GED battery in 1990.

Using Social Security numbers supplied by GED candidates at the time of testing, Social Security Administration (SSA) programmers attached Social Security-taxable earnings data to our GED test-file data, providing valid matches for about nine out of ten dropouts. ${ }^{8}$ The resulting micro-level data set contained demographic and GED test score information collected when the dropouts in the sample attempted the GED in 1990, together with their Social Security earnings records for each year from 1988 to 1995. The SSA does not release individual earnings to researchers. As a result, the SSA used the micro-level data to construct an aggregated data set satisfying SSA confidentiality requirements and our research design. ${ }^{9}$ The final aggr egated data set consists of 990 cells, defined by the state where the GED was attempted,

6. For example, out of the 42 states used in our study, only Louisiana in 1982 , California in 1984, New York in 1985, Arkansas in 1987, and Washington in 1988 changed their GED passing standard between 1980 and 1990.

7. We augment the GED Testing Service data with data from New York, Florida, and Connecticut because these states were missing from the GED Testing Service data.

8. Providing SSNs on the GED test form is voluntary, but inspection of the Florida and Connecticut samples indicates that about 98 percent of examinees 21 and younger (our target group) provide this information.

9. SSA confidentiality regulations require that no information be released in cells where there are fewer than three observations. Other SSA limitations are discussed in the Data Appendix. 
GED score group, gender, and whether the GED candidate was white or minority. ${ }^{10}$ Each cell contained average FICA earnings for a particular year for the individuals in the cell, cell frequency, and the standard deviation of earnings.

Table IV presents summary statistics for the aggregated data. In the table we possess the universe of young dropouts who attempted the GED in 1990 in New York, Florida, and Connecticut, and so, relatively speaking, the number of individuals contributed by those states is large (column 1). The analytic sample is about 70 percent white (column 6) and 55 percent male (column 7). Columns 8 and 9 present mean earnings five years after dropouts attempted the GED battery, and these earnings are generally low. ${ }^{11}$ While not reported here, the variances of 1995 earnings for any particular subset of our sample are generally large relative to the mean, as is typical with annual earnings. Column 2 shows the minimum score group in which individuals would have a GED in a given state, reemphasizing the three different passing standards present in our data. Columns 3, 4, and 5 of Table IV designate whether a state falls into the treatmentgroup or comparison-group in each experiment that we use, demonstrating how some states contribute to the treatment group in one experiment and to the comparison group in another.

We use New York and Florida to form the comparison group in two of our three experiments. We single out these states because New York and Florida data contain the accumulated best scores of dropouts who have either attained a GED or who have "stopped out" as of 1990.12 The 1990 GEDTS data, however, contain only a one-year "snapshot" of GED-attempters, and some unknown portion of individuals with failing scores in the 1990 GEDTS data will have subsequently retaken and passed the battery in years 1991-1995. ${ }^{13}$ Therefore, any comparison group constructed from

10. To avoid small cells in the affected score groups that would be censored by the SSA, we could not stratify more finely on race/ethnicity and on age.

11. Earnings in New York are low compared with those in other states. In additional data we find that the positive earnings of dropouts in New York are the highest of any state, indicating that, in our data, many young dropouts in New York had zero Social Security taxable earnings in 1995.

12. By this we mean that we are certain that nonpassers in the New York and Florida data did not return after 1990 to retake the exams and potentially receivea GED in any of the years prior to our measurement of earnings. In these states, anyone who took any portion of the tests after 1990 would not be included in the data, regardless of their passing status.

13. For example, using the Connecticut and Florida individual-level data, we find that about 70 percent passed the GED on the first try in 1988. Out of those who did not pass, about 40 to 50 percent retested and acquired a GED within two 
TABLE IV

Summary Statistics and Treatment/Comparison-Group Designation by State for Young Dropouts Who Attempted the GED IN 1990

\begin{tabular}{|c|c|c|c|c|c|c|c|c|c|}
\hline \multirow{2}{*}{$\begin{array}{l}\text { State } \\
\text { group }\end{array}$} & \multirow{2}{*}{$\frac{\text { Col. } 1}{N}$} & \multirow{2}{*}{$\begin{array}{l}\text { Col. } 2 \\
\text { Minimum } \\
\text { score } \\
\text { group } \\
\text { for GED }\end{array}$} & \multicolumn{3}{|c|}{$\begin{array}{c}\text { Cols. } 3,4, \& 5 \\
\text { Treatment or } \\
\text { comparison in . . }\end{array}$} & \multicolumn{2}{|c|}{$\begin{array}{l}\text { Cols. } 6 \& 7 \\
\% \text { of sample } \\
\text { who are. . }\end{array}$} & \multicolumn{2}{|c|}{$\begin{array}{c}\text { Cols. } 8 \& 9 \\
\begin{array}{c}\text { Mean } 1995 \\
\text { earnings }\end{array}\end{array}$} \\
\hline & & & Exp3 & Exp3* & Exp4 & White & Male & NoGED & GED \\
\hline$A Z$ & 3457 & 4 & - & $\mathrm{C}$ & $\mathrm{T}$ & $65 \%$ & $57 \%$ & 7176 & 9336 \\
\hline CT & 1692 & 4 & - & - & - & $71 \%$ & $51 \%$ & 8779 & 10413 \\
\hline $\mathrm{FL}$ & 17905 & 5 & C & - & $\mathrm{C}$ & $74 \%$ & $56 \%$ & 7767 & 9694 \\
\hline KY & 1949 & 4 & - & $\mathrm{C}$ & $\mathrm{T}$ & $83 \%$ & $58 \%$ & 6797 & 8149 \\
\hline NY & 19134 & 5 & $\mathrm{C}$ & - & $\mathrm{C}$ & $53 \%$ & $56 \%$ & 6777 & 8764 \\
\hline TN & 1668 & 4 & - & $\mathrm{C}$ & $\mathrm{T}$ & $94 \%$ & $50 \%$ & 8479 & 9079 \\
\hline TX & 5027 & 3 & $\mathrm{~T}$ & $\mathrm{~T}$ & - & $60 \%$ & $51 \%$ & 7755 & 9286 \\
\hline VA & 1657 & 4 & - & $\mathrm{C}$ & $\mathrm{T}$ & $78 \%$ & $59 \%$ & 7905 & 9662 \\
\hline Misc & 2852 & 4 & - & $\mathrm{C}$ & $\mathrm{T}$ & $79 \%$ & $54 \%$ & 7559 & 8813 \\
\hline Atlantic states & 3237 & 4 & - & $\mathrm{C}$ & $\mathrm{T}$ & $75 \%$ & $55 \%$ & 8184 & 10327 \\
\hline New England & 1801 & 4 & - & $\mathrm{C}$ & $\mathrm{T}$ & $91 \%$ & $52 \%$ & 8273 & 9727 \\
\hline North Central & 2313 & 4 & - & $\mathrm{C}$ & $\mathrm{T}$ & $85 \%$ & $55 \%$ & 9031 & 10364 \\
\hline \multicolumn{10}{|l|}{ Low pass } \\
\hline states $^{d}$ & 4138 & 3 & $\mathrm{~T}$ & $\mathrm{~T}$ & - & $76 \%$ & $55 \%$ & 7899 & 8732 \\
\hline \multicolumn{10}{|c|}{ Miscellaneous } \\
\hline states ${ }^{\mathrm{e}}$ & 4202 & 4 & - & $\mathrm{C}$ & $\mathrm{T}$ & $80 \%$ & $55 \%$ & 7750 & 9032 \\
\hline WA and CA & 4713 & 5 & - & $\mathrm{C}$ & - & $64 \%$ & $57 \%$ & 8017 & 9351 \\
\hline \multicolumn{10}{|l|}{ High pass } \\
\hline states $^{f}$ & 4255 & 5 & - & $\mathrm{C}$ & - & $67 \%$ & $55 \%$ & 6258 & 8669 \\
\hline Totalg & 80000 & & & - & - & $69 \%$ & $55 \%$ & - & - \\
\hline
\end{tabular}

a. States AZ through VA had enough observations to serve as their own "state group." Other states had to be grouped into either geographic or other logical groupings due to small numbers of observations. See the Data Appendix for a listing of the states in each group not otherwise detailed here.

b. There were seven different GED passing standards in 1990 that ranged from the low standard represented by score group 3 to that of Wisconsin, which required a mean of 50 and a minimum of 40 .

c. Alaska, Hawaii, Idaho, Montana, Alabama, I owa, Kansas, and N evada.

d. This group is composed of Mississippi, Louisiana, and Nebraska, and together with Texas they comprise the group of states with the lowest passing standard, a mean of 45 or a minimum of 40 .

e. This group is composed of Col orado, Illinois, Pennsylvania, and Minnesota, the only states where there were statistically significant differences between individuals with and without imputed writing scores. (See above and the Data Appendix for a discussion of imputed writing scores in the GEDTS data.)

f. This group is composed of Arkansas, Delaware, Maryland, Oklahoma, South Dakota, and Utah, and along with Washington and California, these states have the same higher standards as do New York and Florida.

g. Note that with about 36,000 observations combined, New York and Florida heavily influence the statistics in this row.

nonpassing GED candidates in the GEDTS data will be contaminated with individuals who subsequently obtained a GED. This occurs in Experiment 3*, and the results from this experiment

years. The result is that the overall pass rate went from 70 percent on the first try in 1988 to an eventual pass rate of about 85 percent by the end of 1990. 
provide a conservative, lower bound estimate of the signaling effect of the GED.

\section{B. Statistical Analyses}

The key treatment-control comparison is captured in the following model describing the annual earnings of dropouts in an unobserved individual-level world:

(1) $Y_{i}=\beta_{0}+\beta_{1}^{\prime} S T_{i}+\beta_{2}^{\prime} S G_{i}+\alpha\left(T_{i} * A_{S G}\right)+\beta_{3}$ Female $+u_{i}$, where

$Y=$ individual i's annual earnings in some year after the GED was attempted;

$\mathrm{ST}=$ vector of state dummies;

$\mathrm{SG}=$ vector of dummies representing the GED score group containing individual $i$;

$\mathrm{T}=1$ if individual $\mathrm{i}$ is in a lower standard treatment state, 0 otherwise;

ASG $=1$ if individual $i$ is in the affected score group and 0 if individual $i$ is in a higher score group, where the "affected score group" is either score group 3 or score group 4 depending on the experiment; ${ }^{14}$

Female $=1$ if individual $\mathrm{i}$ is a female, 0 if a male;

$\mathrm{u}=$ error term, with zero expectation and orthogonal to predictors.

For reasons we explain later, we stratify our data into white and minority dropouts, and we would like to fit equation (1) separately for each of these two race/ethnicity groups. However, we cannot fit the hypothesized model in equation (1) because we do not have individual-level data on earnings. Fortunately, based on equation (1), the parameter of interest, $\alpha$, representing the effect of the GED on the earnings of dropouts whose GED-status is affected by state-of-residence is

(2) $\quad \alpha=E\left[Y_{i} \mid T_{i}=1, A S G_{i}=1\right]-E\left[Y_{i} \mid T_{i}=0, A_{S G}=1\right]$

$$
-\left(E\left[Y_{i} \mid T_{i}=1, A S G_{i}=0\right]-E\left[Y_{i} \mid T_{i}=0, A S G_{i}=0\right]\right),
$$

14. We omit those who score bel ow the affected score group range because, in the GEDTS data, these score groups are contaminated with individuals who have a GED, and whom we cannot identify. This contamination downwardly biases estimates of a. Estimates using these lower score groups are available from the authors upon request. These "contaminated" estimates are consistently lower than our preferred estimates, regardless of the experiment and the racial group. 
suggesting that a method-of-moments estimator of $\alpha$ can be constructed from sample means. This difference-in-differences estimator is

$$
\hat{\alpha}=\left(\bar{Y}_{\mathrm{T}}-\overline{\mathrm{Y}}_{\mathrm{C}}\right)-\left(\overline{\mathrm{Y}}_{\mathrm{THi}}-\overline{\mathrm{Y}}_{\mathrm{CHi}}\right),
$$

where

$\bar{Y}=$ mean earnings of any group;

$T$ indexes the treatment group-individuals in the affected score group who are in a low-passing-standard state in a given experiment, and thus havea GED;

$C$ indexes the comparison group_-individuals in the affected score group who are in a high-passing-standard state, and thus do not havea GED;

THi indexes individuals in treatment states that are in a scoring group higher than the affected score group, and thus have a GED;

$\mathrm{CH}$ indexes individuals in comparison states that are in the same high scoring group as the THi group, and thus also have a GED.

We use all individuals in score groups 5 through 10 to form the high comparison groups, $\mathrm{THI}$ and $\mathrm{CHi}$, in the difference-indifferences estimation. This avoids arbitrarily deciding which score group to use in this capacity and maximizes sample size in the high comparison groups. ${ }^{15}$ Finally, notice that the second difference in the difference-in-differences estimator, $\bar{Y}_{\mathrm{THi}} \bar{Y}_{\mathrm{CHi}}$, removes state fixed effects from the estimate.

We can estimate $\alpha$, and conduct hypothesis tests, using SSA-provided aggregate within-group statistics on earnings. ${ }^{16}$ We identify $\alpha$ using two assumptions. The first is that the differential state GED passing standards generate exogenous variation in GED status. This is embodied in the assumed independence of the interaction and error terms. The second assumption is that equation (1) contains no higher order interactions. Later, we examine empirical evidence regarding violations of these assump-

15. Additional analyses verify that our findings are not qualitatively different when we use any one of the score groups as the high comparison group, as opposed to using everyone simultaneously.

16. The standard errors for the estimator are obtained in the standard manner, with no assumptions of equality of variances across groups. 
tions, confirming that any resulting biases have little impact on our estimates.

In computing our difference-in-differences estimates, we weight the calculation of within-group earnings to account for the different gender distributions within treatment and comparison groups, and across states within these groups. In other analyses not reported here, we confirm that our findings are not sensitive to the choice of weights.

\section{Results}

A. Differencein-Differences Estimates of thel mpact of the GED on the Earnings of Young Dropouts

Table $V$ presents separate estimates of the effect of the GED on 1995 earnings for white and minority dropouts from three different experiments involving young dropouts who attempted the GED in $1990 .{ }^{17}$ We focus initially on estimates generated by experiments 3 and 4 . In these experiments, acquisition of a GED is associated with about a $\$ 1500$ increase in annual earnings for young white dropouts, an increase of approximately 19 percent. The point estimates for whites from the two different experiments ( $\$ 1473$ and \$1531) are remarkably similar given that the states making up the treatment group in each experiment are different.

Both experiments 3 and 4 use New York and Florida as comparison-group states. Experiment 3*, like experiment 3, uses Texas, Louisiana, Mississippi, and N ebraska as treatment states. However, experiment $3^{*}$ excludes New York and Florida and instead uses states from the GEDTS data in the comparison groups, including states where the GED is awarded in score group 4. As explained above, when GEDTS data are used to construct the comparison group, the group will be contaminated by an unknown number of individuals who obtained a GED after 1990. Because of this, the 1995 earnings of the comparison group will be inflated (assuming a positive treatment effect of the GED on earnings). Thus, the $\$ 907$ difference-in-differences estimate in experiment $3^{*}$ represents a downwardly biased, conservative estimate of the impact of the GED on earnings.

17. Preliminary analyses indicated that results for white males and females were similar and the results for minority males and females were similar. Thus, to increase statistical power, we aggregated across the genders, retaining the white-minority distinction. 
TABLE V

Difference-In-Differences Estimates of THE IMPACt OF THE GED ON 1995 Earnings of Dropouts Who Tested in 1990 (Standard ERrors Are

in Parentheses.)

\begin{tabular}{|c|c|c|c|c|c|c|c|c|c|}
\hline & \multicolumn{3}{|c|}{ Experiment 4} & \multicolumn{3}{|c|}{ Experiment 3} & \multicolumn{3}{|c|}{ Experiment 3* } \\
\hline & \multicolumn{2}{|c|}{$\begin{array}{l}\text { State passing } \\
\text { standard is }\end{array}$} & \multirow{2}{*}{$\begin{array}{l}\text { Low-High } \\
\text { standard } \\
\text { contrast }\end{array}$} & \multicolumn{2}{|c|}{$\begin{array}{l}\text { State passing } \\
\text { standard is }\end{array}$} & \multirow{2}{*}{$\begin{array}{c}\text { Low-High } \\
\text { standard } \\
\text { contrast }\end{array}$} & \multicolumn{2}{|c|}{$\begin{array}{l}\text { State passing } \\
\text { standard is }\end{array}$} & \multirow{2}{*}{$\begin{array}{c}\text { Low-High } \\
\text { standard } \\
\text { contrast }\end{array}$} \\
\hline & Low & High & & Low & High & & Low & High & \\
\hline \multicolumn{10}{|c|}{ Panel A: Whites } \\
\hline \multicolumn{10}{|c|}{$\overline{\text { Test score is }}$} \\
\hline Low & $\begin{array}{l}9628 \\
(361)\end{array}$ & $\begin{array}{l}7849 \\
(565)\end{array}$ & $\begin{array}{l}1779 \\
(670)\end{array}$ & $\begin{array}{l}9362 \\
(400)\end{array}$ & $\begin{array}{l}7843 \\
(312)\end{array}$ & $\begin{array}{l}1509 \\
(507)\end{array}$ & $\begin{array}{l}9362 \\
(400)\end{array}$ & $\begin{array}{l}8616 \\
(219)\end{array}$ & $\begin{array}{c}746 \\
(456)\end{array}$ \\
\hline High & $\begin{array}{l}9981 \\
(80)\end{array}$ & $\begin{array}{c}9676 \\
(65)\end{array}$ & $\begin{array}{c}305 \\
(103)\end{array}$ & $\begin{array}{l}9143 \\
(135)\end{array}$ & $\begin{array}{c}9165 \\
(63)\end{array}$ & $\begin{array}{l}-23 \\
(149)\end{array}$ & $\begin{array}{l}9143 \\
(135)\end{array}$ & $\begin{array}{l}9304 \\
(135)\end{array}$ & $\begin{array}{l}-162 \\
(150)\end{array}$ \\
\hline $\begin{array}{l}\text { Differen } \\
\text { for } v\end{array}$ & $\begin{array}{l}\text {-differe } \\
\text { es }\end{array}$ & ces & $\begin{array}{l}1473^{*} \\
(678)\end{array}$ & & & $\begin{array}{c}1 \overline{531^{*} *} \\
(529)\end{array}$ & & & $\begin{array}{l}\overline{907 \sim} \\
(481)\end{array}$ \\
\hline Low & $\begin{array}{l}6436 \\
(549)\end{array}$ & $\begin{array}{l}8687 \\
(690)\end{array}$ & $\begin{array}{c}-2252 \\
(882)\end{array}$ & $\begin{array}{l}7005 \\
\text { (347) }\end{array}$ & $\begin{array}{l}7367 \\
(347)\end{array}$ & $\begin{array}{l}-363 \\
(495)\end{array}$ & $\begin{array}{l}7005 \\
(347)\end{array}$ & $\begin{array}{l}6858 \\
(290)\end{array}$ & $\begin{array}{c}147 \\
(452)\end{array}$ \\
\hline High & $\begin{array}{l}7560 \\
(184)\end{array}$ & $\begin{array}{l}8454 \\
(96)\end{array}$ & $\begin{array}{l}-894 \\
(207)\end{array}$ & $\begin{array}{l}7782 \\
(214)\end{array}$ & $\begin{array}{l}8375 \\
(93)\end{array}$ & $\begin{array}{l}-593 \\
(233)\end{array}$ & $\begin{array}{l}7782 \\
(214)\end{array}$ & $\begin{array}{l}7568 \\
(133)\end{array}$ & $\begin{array}{c}214 \\
(252)\end{array}$ \\
\hline $\begin{array}{l}\text { Differen } \\
\text { for } r\end{array}$ & $\begin{array}{l}\text {-differe } \\
\text { rities }\end{array}$ & & $\begin{array}{l}-1357 \\
(906)\end{array}$ & & & $\begin{array}{l}\overline{231} \\
(548)\end{array}$ & & & $\begin{array}{l}-67 \\
(518)\end{array}$ \\
\hline
\end{tabular}

** = significant at the 0.01 level, $*=$ significant at the 0.05 level, $\sim=$ significant at the 0.10 level

Experiment 4: Test Score Low: score group $=4$; Test Score High score groups $=5-10$

Passing Standard Low: 35 minimum score and 45 mean score; Passing Standard High: 40 minimum score and 45 mean score

Low Passing Standard states: All states except for TX, LA, MS, NE, FL, NY, CA, WA, and CT; High Passing Standard states: NY and FL.

Experiment 3: Test Score Low: score group $=3$; Test Score High score groups $=5-10$

Passing Standard Low: 40 minimum score or 45 mean score; Passing Standard High: 40 minimum score and 45 mean score

Low Passing Standard states: TX, LA, MS, and NE; High Passing Standard states: NY and FL.

Experiment 3*: Test Score Low: score group $=3$; Test Score High: score groups $=5-10$.

Passing Standard Low: 40 minimum score or 45 mean score; Passing Standard High: 35 minimum score and 45 mean score.

Low Passing Standard states: TX, LA, MS, and NE; High Passing Standard states: all states except TX, LA, MS, NE, NY, FL, and CT.

The results for nonwhite dropouts differ sharply from the results for white dropouts. The three experiments yield no statistically significant evidence that acquisition of a GED results in higher earnings for minority dropouts. We return to the minority results later. Based on the results from experiments 4, 3, and 3*, our estimates are robust to the use of different treatment and comparison groups.

\section{B. Timing of GED Treatment Effects}

To avoid underestimating the impact of the GED by measuring earnings too close to receipt of the credential, we have 
concentrated on using the 1995 earnings of young dropouts who attempted the GED in 1990 as our outcome measure. To explore both pretreatment earnings differences as well as the possibility that benefits accruing to GED-acquisition do indeed take time to develop, we construct equivalent difference-in-differences estimates using earnings in the years 1988-1989 and 1991-1995. These comparisons continue to use 1990 test-takers as the analytic sample, and we concentrate on white dropouts.

Figures I-III show year-by-year difference-in-differences estimates for experiments 4, 3, and 3*. Posttreatment earnings in Figures I and II (years 1-5 after the GED attempt) suggest that it takes time for the GED to pay off for young white dropouts. Figure I shows that, in the first two years after GED-acquisition, GED-holders actually earn less than uncredentialed dropouts with the same GED scores. Over time GED-holders in the treatment group gain on their uncredentialed counterparts in the comparison group, so that by the fifth year after GED-acquisition, they are earning \$1473 more per year. And, while it appears from Figure II that treatment individuals in experiment 3 can make the GED pay off sooner than those in experiment 4, the trends are the same. Estimates from experiment $3^{*}$ are not well suited for studying the timing of GED effects because each year after 1990 the comparison group becomes increasingly contaminated by retesters who return to obtain a GED. We consider pretreatment earnings in a later section.

\section{Threats to Identification in the Natural EXPERIMENT ESTIMATES}

There are four general sources of potential bias in our primary results in Table V. First, to the extent that individuals use the GED to access postsecondary education or training, our failure to control for these human capital effects would lead to overestimates of the signaling value of the GED. Also, there are three different types of endogeneity bias that could affect our estimates. We explore these potential biases in this section.

\section{A. Postsecondary Education and Training Effects}

Most academic postsecondary programs and many training programs, as well as the loan and grant programs that can help pay for them, require a school leaving certificate. For most dropouts who desire admittance to these programs, the GED serves this purpose. It follows that acquisition of a GED could lead 
Figure I: Experiment 4

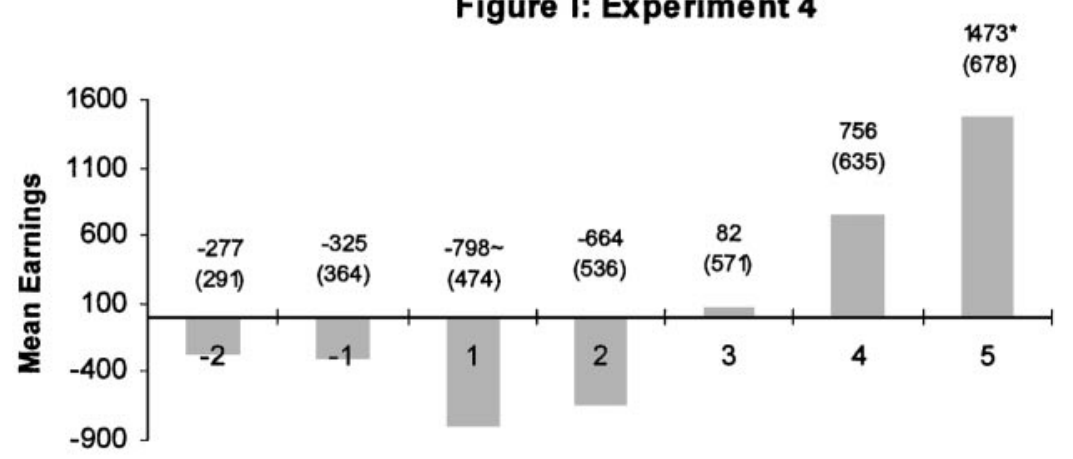

\section{Year from Test}

Figure II: Experiment 3

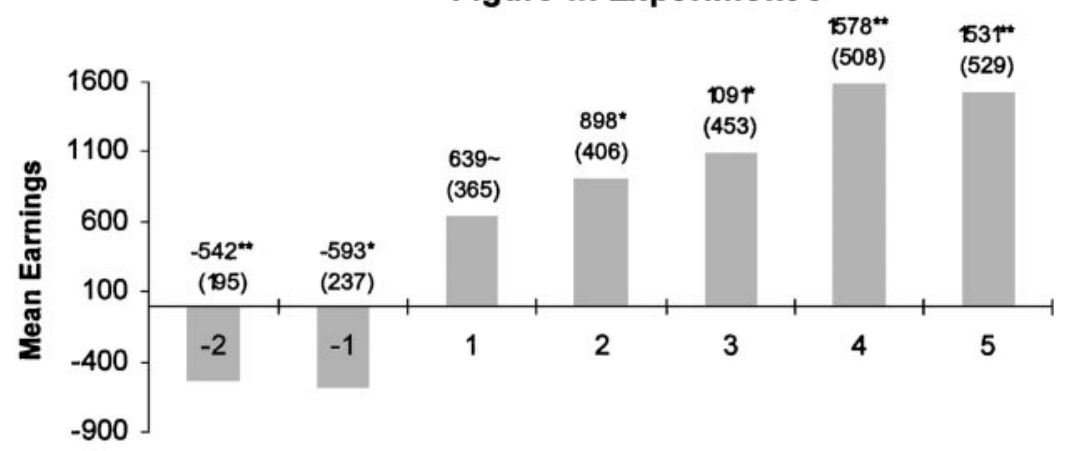

Year from Test

Figure III: Experiment 3*

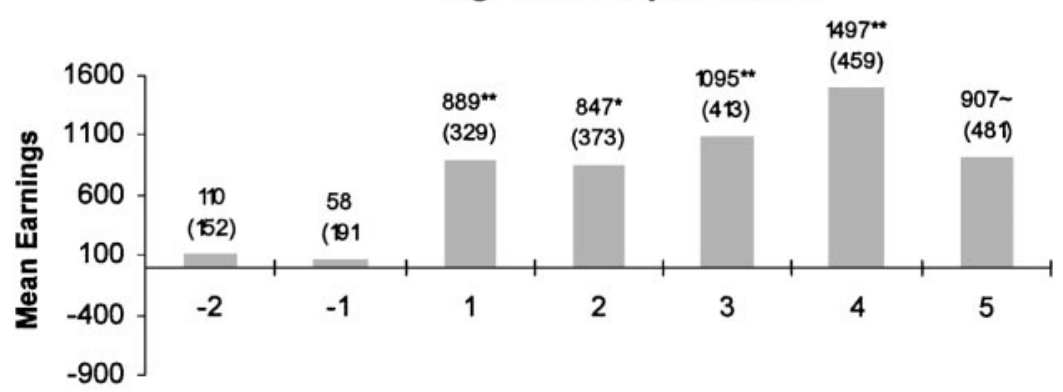

Year from Test

FIGURES I-III

Pretreatment and first through fifth year Difference-in-Differences Estimates for Young White Dropouts. (** = Significant at the 0.01 Level; * = Significant at the 0.05 Level; = Significant at the 0.10 Level.) 
to higher average levels of human capital through increased access to postsecondary education and training programs. Since we do not account for this potential human capital effect, interpretation of our estimates as returns to a signal could overstate the case. Analysis of other data indicates, however, that thesetypes of human capital effects do not seriously threaten the signaling interpretation of our estimates.

In HSB data we find that the least skilled GED-hol ders (those in the lowest quartile of the sophomore math test) accumulated on average less than five postsecondary credits by age 28 . Based on an academic year being equal to 30 credits, this is one-sixth of an academic year. Other authors [Kane and Rouse 1995; Murnane, Willett, and Boudett 1999] estimate that a year of postsecondary academic work has a return of about 5 percent relative to high school graduation. This suggests that less than one percentage point $(1 / 6 \times 0.05)$ of any estimate based on low skilled GEDholders might be due to postsecondary education human capital accumulation rather than labor market signaling.

Regarding postsecondary training, Murnane, Willett, and Boudett [1997] use the NLSY to show that both male and female GED-holders are more likely to obtain off-the-job training (i.e., training in a government-sponsored program or a proprietary school) than are comparable uncredential ed dropouts. ${ }^{18}$ However, in later work [Murnane, Willett, and Boudett 1999] they al so find no effect of this off-the-job training on the wages of male GEDholders, and Boudett [1998] finds no effect of off-the-job training on the wages of female GED-holders. Taken together, these analyses suggest that neither postsecondary education nor offthe-job training carries substantial earnings effects for low skilled dropouts who are on the margin of passing the GED exams.

\section{B. Endogeneity Bias Associated with Individual Behavior}

Interpreting the results in Table $V$ as the causal impact of the GED signal on earnings rests on an assumption that our treatment and comparison groups are balanced on unobservable characteristics that might influence their earnings. If the different passing standards influence individual behavior in systematic ways, then this assumption may be violated. There are three decisions that might be influenced by differential GED passing

18. Since the GED signal may help dropouts obtain jobs that offer training, any returns to post-GED on-the-job training are returns to the signaling value of the GED. 
standards across states: the decision to attempt the test, the decision to migrate to another state, and the decision about how much effort to exert on the test. Each of these potential decisions has different implications for our identification strategy.

First, when faced with higher standards, some individuals on the margin who would otherwise test may elect not to attempt the GED battery. Assuming that this behavior is negatively correlated with productivity-enhancing traits such as persistence, selfconfidence, and motivation, then this type of selection would result in an overestimate of the mean earnings of potential GED-holders in comparison group states. The net effect would be a downward bias in the estimated effect of the GED on earnings.

Endogenous migration decisions are a problem if more motivated dropouts tend to migrate to lower standard states in order to increase their chances of passing the exams or because of other factors that are also related to earnings. We examine this possibility by examining the migration patterns of dropouts in the NLSY.

Rows 1, 2, and 3 in Panel A of Table VI represent the mobility patterns of GED-holders who were in low, medium, and high

TABLE VI

State Migration Patterns between Low, Medium, and High ged Passing Standard States for GED-Holders and Uncredentialed Dropouts in the NLSY (Weighted Tabulations, Row Percentages Sum to 100)

\begin{tabular}{|c|c|c|c|}
\hline \multirow{2}{*}{$\begin{array}{c}\text { Panel A: } \\
\text { GED-holders } \\
\text { Passing standard in state } \\
\text { of residence at age } 14\end{array}$} & \multicolumn{3}{|c|}{$\begin{array}{l}\text { GED passing standard in state of } \\
\text { residence in year of GED acquisition }\end{array}$} \\
\hline & Low & Medium & High \\
\hline Low & $89.0 \%$ & $8.5 \%$ & $2.6 \%$ \\
\hline Medium & $3.4 \%$ & $90.9 \%$ & $5.6 \%$ \\
\hline High & $2.1 \%$ & $8.1 \%$ & $89.9 \%$ \\
\hline $\begin{array}{l}\text { Panel B: } \\
\text { Uncredentialed dropouts }\end{array}$ & \multicolumn{3}{|c|}{$\begin{array}{l}\text { GED passing standard in } \\
\text { state of residence at age } 21\end{array}$} \\
\hline of residence at age 14 & Low & Medium & High \\
\hline Low & $86.7 \%$ & $6.6 \%$ & $6.8 \%$ \\
\hline Medium & $2.5 \%$ & $91.9 \%$ & $5.6 \%$ \\
\hline High & $1.5 \%$ & $9.0 \%$ & $89.5 \%$ \\
\hline
\end{tabular}

a. To match the age group used in this paper, the percentages in Panel A are based on the 512 GED-holders in the NLSY who were aged 16-21 when they obtained their GED and who obtained the credential in 1979 or later. The migration patterns of all GED-holders in the NLSY are very similar to this younger age group. We excluded those dropouts who obtained their GED prior to 1979 because we cannot determine the state of residence at GED acquisition for earlier years. Finally, there are five states (SC, NM, ND, WI, and NJ ) with standards that do not fit our low, medium, and high categories. 
standard states (respectively) at age fourteen. The percentages across the rows sum to 100 , so that 89 percent of the individuals who started out in low standard states were still in a low standard state when they obtained their GED, 8.5 percent had moved to a medium standard state, and 2.6 had moved to a high standard state by the time of GED acquisition.

Systematic migration from high to low standard states would be indicated by relatively little migration out of the upper left-hand cell and relatively more migration to the left out of both the middle cell of the table and the lower right-hand cell of the table. Instead, we see that about 10 percent of GED-holders, regardless of the passing standards in their state of residence at age fourteen, obtain their GED in a state with a higher or lower standard. Furthermore, among those GED-holders who do move between age fourteen and GED acquisition, there is no evidence of systematic movement to lower standard states.

As a further check on the mobility patterns of GED-holders, Panel B of Table VI presents the migration probabilities (as of age 21 ) of the uncredentialed dropouts in the NLSY. The results are similar to those of Panel $A$, again suggesting that there are no systematic links between GED state passing standards and the migration decisions of young dropouts. ${ }^{19}$

The third source of bias that could result from individual responses to state passing standards relates to test-taking effort. The concern is that individuals in our treatment group may have higher unobserved skills than individuals in the comparison group. This situation could occur if some of the more highly skilled dropouts in the lower standard states exerted just enough effort to narrowly pass the exams. In this case our treatment group would be contaminated with individuals whose skills were higher than their GED scores indicated. We can explore this potential source of bias with our data.

To do this, we assume that some individuals in lower standard states whose true skills are higher than what is required to "just pass" exert just enough effort to pass the GED battery. As a result, some of these higher ability individuals are in score groups 3 or 4 in our data. Figure IV displays the sorting that would result

19. A separate problem would arise if GED candidates did not migrate, but simply crossed state lines to attempt the test in a lower standard state. We note that all states have residency requirements to attempt the GED. Furthermore, the chief state GED officer in Texas informed us that proof of residency was often requested in testing sites situated close to the borders with other states [Erwin 1999]. 


\begin{tabular}{|c|c|c|c|c|c|c|c|c|c|c|}
\hline \multirow[b]{3}{*}{$\begin{array}{l}\text { Unobserved sorting of true } \\
\text { skills among... }\end{array}$} & \multicolumn{10}{|c|}{ Observed GED score groups } \\
\hline & 1 & 2 & 3 & 4 & 5 & 6 & 7 & 8 & 9 & 10 \\
\hline & & & & & & & & & & \\
\hline low standard states. ${ }^{a}$ & 1 & 2 & $3,5,6^{c}$ & $4,5,6$ & 5 & 6 & 7 & 8 & 9 & 10 \\
\hline medium standard states. ${ }^{b}$ & 1 & 2 & 3 & 4.5 .6 & 5 & 6 & 7 & 8 & 9 & 10 \\
\hline
\end{tabular}

a. States where the GED is awarded in score groups 3 and above.

b. States where the GED is awarded in score groups 4 and above.

c. We assume that there are no true $4 \mathrm{~s}$ in score group 3 in the low standard states, because these are individuals who

would have to lower their mean score at the same time that the raised their minimum score. This is not a clear example of the reduced testing effort hypothesis that motivates this section.

\section{FIGURE IV}

Score-Group Sorting around L ow and Medium GED Passing Standards (Shaded Cells = Score Groups Where the GED is Awarded)

from this assumption. The top row of Figure IV depicts the ten observed GED score groups. The next two rows depict hypothetical distributions of true, underlying skills across the ten GED score groups used in this study when some higher ability individuals exert just enough effort to pass. The middle row illustrates a hypothetical distribution of true skills for low standard states (where the GED cutoff is at score group 3) and the bottom row illustrates this situation for medium standard states (where GED cutoff is at score group 4). As an example, according to the middle row of F igure IV, observed score group 3 in low standard states not only has individuals whose true underlying skills place them in this score group ("true 3s"), but also individuals with higher skills ("true 5s and 6s") who exerted just enough effort to pass. This type of "ability contamination" of score group 3 in the low standard states would cause us to overestimate the effect of the GED on earnings.

We can adjust our estimates to account for this type of differential effort by assuming the following:

(1) the observed proportion of individuals in the affected score group in the higher standard states represents what the true skill distribution in the affected score group in the lower standard states would be in the absence of differential effort across the states ${ }^{20}$ (e.g., for experiment

20. As an anonymous reviewer pointed out, this assumption would likely not hold if there were differential participation rates across lower and higher standard states. However, we assume that fewer individuals attempt in the higher standard states. If more were to attempt, then presumably the percentage who "just fail" in these higher standard states would go up, and based on the al gorithm we describe, 
3 the correct proportion of true 3s in the low standard states is given by the proportion of observed $3 \mathrm{~s}$ in the higher standard states), and

(2) the mean earnings of higher skilled individuals who score less than their true abilities are the same as the observed mean earnings of similarly skilled individuals who sort themsel ves into their true score groups.

To illustrate how we use these assumptions to generate adjusted estimates, consider experiment 3 using just Texas, a low standard state, and Arizona, a medium standard state. Individuals in Texas in score group 3 havea GED, while those in Arizona in score group 3 just missed getting a GED. Say, that we see 4 percent of the distribution of GED attempters in Texas in score group 3, but only 1 percent of the distribution of attempters in Arizona in that score group. We are worried that the larger percentage in Texas is the result of higher ability individuals exerting just enough effort to pass in that state, placing them in score group 3. As a result, the observed earnings in score group 3 in Texas are a weighted average of score group 4 types and higher ability types, and are biased upward from what they would be if everyone scored according to their underlying ability.

To "purge" the estimated earnings in score group 3 of the earnings of the higher ability types, we will assume, based on what we observe in Arizona, that out of the 4 percent in score group 3 in Texas, only one-fourth are true score group 3 types, while the remaining three-fourths are actually, say, true "5s." If we assign to the three-fourths who we assumed are $5 \mathrm{~s}$, the observed mean earnings for score group 5 in Texas, we can then estimate the earnings of the one-fourth whom we believe to be true 3s. These are our adjusted earnings estimates.

Adjusted estimates based on these assumptions and algorithm are in Table VII. We assume that the treatment group in each of the experiments is primarily contaminated by true $5 \mathrm{~s}$ or true 6s, and so we empl oy three different assumptions in Table VII regarding the mix of $5 \mathrm{~s}$ and $6 \mathrm{~s}$. First, we assume no contamination, which simply redisplays our original results from Table $V$ for ease of comparison. N ext, weassume a 50-50 mix of 5s and 6s, and then to get a very conservative, lower-bound estimate, we assume only $6 s$ contaminate the treatment group.

our adjusted estimates would be closer to our unadjusted estimates. Thus, if anything, we believe that differential participation gives us conservative adjusted estimates. 
TABLE VII

Adjusted Estimates in the Presence of Differential Testing Effort across Low and High Standard States for Young White Dropouts (Standard ERrors Are in Parentheses.)

\begin{tabular}{|c|c|c|c|c|c|c|c|}
\hline & \multicolumn{5}{|c|}{$\begin{array}{l}\text { Adjusted numbers } \\
\text { of observations }\end{array}$} & \multicolumn{2}{|c|}{$\begin{array}{l}\text { Adjusted estimates under } \\
\text { different skill composition } \\
\text { assumptions }\end{array}$} \\
\hline & $p_{c}{ }^{a}$ & $\mathrm{~N}_{\text {treat }}{ }^{\mathrm{b}}$ & $\mathrm{N}_{\mathrm{T}}{ }^{\mathrm{c}}$ & $\mathrm{p}_{\mathrm{c}}\left(\mathrm{N}_{\text {treat }}\right) \mathrm{d}$ & $\begin{array}{c}{\left[\mathrm{N}_{\mathrm{T}}-\right.} \\
\left.\mathrm{p}_{\mathrm{c}}\left(\mathrm{N}_{\text {treat }}\right)\right] \mathrm{e}\end{array}$ & $\begin{array}{l}\text { Treatment group } \\
\text { contamination } \\
\text { assumption } \\
\text { of . . }\end{array}$ & $\begin{array}{l}\text { Adjusted } \\
\text { estimate }\end{array}$ \\
\hline \multirow[t]{3}{*}{$\begin{array}{l}\text { Experiment } \\
4\end{array}$} & 0.011 & 18332 & 653 & 202 & 451 & & \\
\hline & & & & & & no contamination ${ }^{f}$ & $\begin{array}{l}1473^{*} \\
(678)\end{array}$ \\
\hline & & & & & & $\begin{array}{l}\text { the contamination } \\
\text { is } 50 \% \text { true } 5 \mathrm{~s} \\
\text { and } 50 \% \text { true } 6 \mathrm{~s} \text {. } \\
\text { all contamination } \\
\text { is from true } 6 \mathrm{~s} \text {. }\end{array}$ & $\begin{array}{c}1166 \\
(1416) \\
\\
612 \\
(1526)\end{array}$ \\
\hline \multirow[t]{4}{*}{$\begin{array}{l}\text { Experiment } \\
3\end{array}$} & 0.031 & 6137 & 471 & 190 & 281 & & \\
\hline & & & & & & no contamination & $\begin{array}{c}1531^{* *} \\
(529)\end{array}$ \\
\hline & & & & & & $\begin{array}{l}\text { contamination is } \\
50 \% \text { true } 5 \text { s and } \\
50 \% \text { true } 6 \text { s. }\end{array}$ & $\begin{array}{c}1715 \\
(1138)\end{array}$ \\
\hline & & & & & & $\begin{array}{l}\text { all contamination } \\
\text { is from true } 6 \mathrm{~s} \text {. }\end{array}$ & $\begin{array}{l}1374 \\
(1219)\end{array}$ \\
\hline \multirow[t]{4}{*}{$\begin{array}{l}\text { Experiment } \\
\qquad 3 * g\end{array}$} & 0.062 & 6137 & 471 & 380 & 91 & & \\
\hline & & & & & & no contamination & $\begin{array}{l}907 \sim \\
(481)\end{array}$ \\
\hline & & & & & & $\begin{array}{l}\text { contamination is } \\
50 \% \text { true } 5 \mathrm{~s} \text { and } \\
50 \% \text { true } 6 \mathrm{~s} \text {. }\end{array}$ & $\begin{array}{c}936 \\
(568)\end{array}$ \\
\hline & & & & & & $\begin{array}{l}\text { all contamination } \\
\text { is from true } 6 \mathrm{~s} \text {. }\end{array}$ & $\begin{array}{c}881 \\
(573)\end{array}$ \\
\hline
\end{tabular}

** = significant at the 0.01 level $; *$ = significant at the 0.05 level.

a. $\mathrm{p}_{\mathrm{c}}=$ the observed proportion of individuals from high standard states in the affected score group

b. $\mathrm{N}_{\text {treat }}=$ the total number of observations in the treatment states, across all score groups.

c. $\mathrm{N}_{\mathrm{T}}=$ the number of observations in the affected score group in the lower standard states.

d. The assumed number of treatment group individuals with the correct true score.

e. The assumed number of treatment group individuals with true scores that would place them in score group 5 or 6; these are the "contaminating" individuals.

$\mathrm{f}$. We include our original estimates in this table (the estimates we obtain under an assumption of no contamination) for ease of comparison.

g. The mean earnings of score group 5 for the treatment states in this experiment are actually slightly lower than the mean earnings of the treatment group here, and so a calculation using the earnings of true $5 \mathrm{~s}$ would result in a higher adjusted estimate. 
The simple story from Table VII is that while all of the adjusted estimates are noisy, the point estimates in Table VII are not far from our original difference-in-differences estimates displayed in Table V. It is only when we assume that all of the 451 "contaminants" in the affected score group in experiment 4 are true 6s that our estimates are driven substantially down (to \$612). Under a more reasonable assumption that the contamination is equally spread between $5 s$ and $6 s$, the original estimate falls 20 percent to $\$ 1166$. Meanwhile, in experiments 3 and $3^{*}$, the stronger contaminating assumption yields adjusted estimates that are only 10 and 3 percent below the original estimates.

In summary, differential effort across low and high standard states may lend an upward bias to our estimates. The evidence, however, is that the magnitude of this bias, especially in experiments 3 and $3^{*}$ is not so severe as to discredit our original estimates.

\section{Endogeneity Bias Associated with StateBehavior}

A second area of potential bias consists of differential state policies between low and high standard states. We examine two different types of policies that would bias our results: state minimum wages and state course graduation requirements.

If states with lower GED standards tended to have higher minimum wages, then our estimates could be biased upward. The reasoning is as follows. It could be that higher scoring GEDholders are not generally affected by minimum wage laws (as a result of their relatively higher skills), while lower scoring GED-holders are. If high minimum wage states are states that systematically have relatively low GED passing standards, then our treatment group individuals may have higher earnings relative to the comparison group for reasons not associated with the effect of the GED on earnings.

An examination of the data suggests that this is not a serious concern, however, simply because there is little variation in 1995 state minimum wages. Most states in the United States in 1995 had a minimum wage of $\$ 4.25$. Only nine states had higher minimum wages, ranging up to $\$ 5.30$ in Alaska. However, none of the four states in our lowest passing standard category had a minimum wage higher than $\$ 4.25$, and states with higher minimum wages are relatively equally divided between low and high passing standard states.

One could argue that it is the "effective minimum" wage, 
rather than the absolute minimum, that is critical for our analyses. Lee [1999] shows that the same absolute minimum wage can differentially compress wages at the bottom end of the wage distribution in low versus high wage states. If lower GED passing standard states arealso systematically lower wage states, then this type of wage compression might cause the wages of low scoring GED-hol ders (those at the margin of passing) and higher scoring GED-holders to be closer in low standard states, biasing our estimates upward. This type of wage effect is essentially a state-skill interaction among GED-holders that is not included in our model. In the subsection on "Employer Behavior" which follows, we present evidence suggesting that missing state-skill interactions are not important factors in explaining our results.

Another potential policy difference that could affect our estimates concerns high school graduation requirements. Higher graduation requirements could be associated with higher dropout rates. As a result, the underlying ability of the pool of dropouts could be different in states with different high school graduation requirements. In particular, if states with Iow GED passing standards have systematically higher graduation requirements for high school, then unobserved ability and motivation in the pool of dropouts in these states may be greater than in other states. In this case, our estimates would have an upward bias.

Our examination of course graduation requirements in 1990 shows, however, that lower GED passing standard states had lower course graduation requirements rather than higher ones. The mean number of Carnegie units ${ }^{21}$ required for graduation by GED passing standard was 18.4 in thelower standard states, 19.3 in the medium standard states, and 20 in the higher standard states. Thus, to the extent that there is a systematic relationship between course graduation requirements and GED passing standards, it does not work in a direction that would lead to an upward bias in our results.

\section{Endogeneity Bias Associated with Employer Behavior}

Finally, it could be that employers behave differently in low versus high GED passing standard states in ways that would bias

21. A Carnegie unit is a unit for measuring the amount of high school academic work by the number of classroom hours spent in one subject. Developed in 1899 by a committee of the $\mathrm{N}$ ational E ducation Association, one Carnegie unit in a subject equals 120 classroom hours lasting 40 to 60 minutes each and meeting four to five times a week, 36 to 40 weeks during the school year. M ost high schools require sixteen Carnegie units per subject for graduation, including required courses such as English, mathematics, American history, and science. 
our estimates. These types of biases show up as omitted interactions in our model. In particular, omitted state-score or stateGED interactions are of concern. State-score interactions that favor high-scoring dropouts in high-standard states would bias our estimates upward, while interactions that favor high-scoring dropouts in low-standard states would bias our estimates downward. State-GED interactions that favor GED-holders in high standard states would bias our estimates upward, while such interactions that favor GED-hol ders in low standard states would bias our estimates downward.

It is possible that employers in states where the GED-passing standard is relatively high give more credence to and place more emphasis on the credential than do employers in low standard states. In this case, ceteris paribus, GED-hol ders would earn more on average in high standard states than similar GED-holders in lower standard states, and this type of mechanism would causean upward bias in our estimates.

Ex ante, we cannot sign the bias associated with possible state-score interactions. We can, however, bring ex post evidence to bear on the question, fitting models where we let the effect of GED test scores, as captured by a variable constructed to approximate a continuous GED score, have different slopes in low, medium, and high standard states. ${ }^{22}$ Table VIII shows estimates from a model fitted over cells representing score groups above the GED passing standard in each state. This model, fit separately for whites and minorities, allows for fixed state effects, a linear effect of GED test score, and then different slopes for GED test score in each of the three different groups of states defined by low, medium, and high GED passing standards.

The nonsignificant coefficient estimates on the passing standard by score interactions suggest that state-skill interactions are not a serious problem for our estimates. Furthermore, the point estimates, imprecise as they are, indicate that any stateskill interactions would tend generally to favor more highly skilled individuals in higher standard states.

These results, combined with the most plausible state-GED interaction effects, suggest that any bias from either or both of the two effects would bias our estimates upward. To assess how serious any total bias from these effects might be, we use the squares fitting of the model in the Statistical Appendix. 
TABLE VIII

Weighted Least Squares Regressions Testing for State-Skill Interactionsa (Dependent Variable Is the Cell Mean of 1995 Annual Earnings, and Standard Errors Are in Parentheses.) ${ }^{b}$

\begin{tabular}{lcc}
\hline \hline & Whites & Minorities \\
\hline Intercept & $10385^{* *}$ & 5178 \\
& $(1765)$ & $(3443)$ \\
Female dummy & $-4316^{* *}$ & $-1429^{* *}$ \\
& $(138)$ & $(269)$ \\
GED score & 27.2 & 72.0 \\
& $(34.0)$ & $(69.0)$ \\
GED score* medium states dummy & 54.8 & -14.8 \\
& $(40.2)$ & $(87.0)$ \\
GED score* high states dummy & 21.5 & 99.1 \\
& $(45.0)$ & $(86.0)$ \\
State dummies & Yes & Yes \\
F-test of Ho & & \\
GED score* medium states and & & \\
GED score* high states interactions are jointly zero & 0.347 & 0.273 \\
Number of cells & 266 & 192 \\
Number of individual level observations & 28,193 & 7,778 \\
\hline \hline
\end{tabular}

** = significant at the 0.01 level; $*=$ significant at the 0.05 level; $\sim=$ significant at the 0.10 level.

a. Low, medium, and high refer to states with low, medium, and high GED passing standards. Low standard states are the omitted group.

b. Construction of the weights and our use of the cell mean data is described in the Statistical Appendix.

c. The "GED score" variable is the within-state average of the GED mean score (the mean of the five tests in the GED battery) in each GED score group. The models are fit using only GED score groups 5-10 and using all available states.

results from experiments 3 and 4 in Table $V$. We expect any upward bias due to omitted interactions to be greater in experiment 3 than in experiment 4 . The reason is that experiment 3 uses treatment states with the lowest standards in the United States in comparisons with the high standard states of New York and Florida, while experiment 4 uses treatment states with medium standards in comparisons with New York and Florida. Thus, the spread between the experiment 3 and experiment 4 estimates gives us some measure of how our results are being affected by the total bias attributable to omitted interactions. ${ }^{23}$ That spread,

23. This result rests not only on our stated assumption regarding the direction of the bias of the state-test-score interactions, but also on the assumptions that (1) any state-test-score interaction is monotonically increasing in test scores and (2) that at least within the narrow scoring range (score groups 3 and 4) represented by the two experiments, the treatment effect is the same. We think both of these assumptions are reasonable, given that we are looking at a relatively well-defined and narrowly defined sample: namely, high school dropouts who score above a certain range on the GED battery of exams. 
however, is less than 4 percent ( $\$ 1473$ versus $\$ 1531$ ). Therefore, we conclude that omitted interaction bias cannot go far in explaining our estimates.

In summary, as with almost any quasi-experimental setting, there are scenarios under which our identifying assumptions would not hold. We have examined the most plausible violations of our identifying assumptions and have found our estimates for white dropouts to be robust to various specification tests.

\section{E. Pretreatment Contrasts}

As a final specification check we examine pretreatment difference-in-differences contrasts. In general, a necessary, but not sufficient, condition for the validity of inferences drawn from an experiment is that there be no pretreatment differences between treatment and comparison outcomes. Figures I and III show no statistically discernible pretreatment differences in the mean earnings of the treatment and comparison groups in experiments 4 and $3^{*}$. In particular, point estimates of pretreatment earnings comparisons in experiment 3* (\$110 and \$58) are almost zero. In contrast, Figure II shows that the pretreatment comparisons in experiment 3 are negative and statistically significant. We might therefore expect the treatment group to fare worse than the comparison group in the absence of treatment, suggesting that estimates of the treatment effect may be downwardly biased with these groups.

\section{Results for Minority Dropouts}

Unlike our findings for whites, we find no statistically significant GED-effect for minority group members. We discuss two potential explanations for these differential minority results.

Using a separate data set from Florida that allows us to determine the testing center at which individuals took the GED exams, we find that about 17 percent of the 16-21 year-old minority males in Florida who obtained their GED in 1995 (the earliest year available in these data) did so while incarcerated. The comparable figure for young white males is 4 percent, and for white females and minority females the figures are 0.3 and 1 percent, respectively. Thus, one explanation for our minority results may lie in the relatively high proportion of young minority males who obtain their GED while incarcerated. 
There are two complementary reasons why individuals in our data who obtained their GED while incarcerated might have depressed earnings relative to individuals who obtained it in a more conventional setting. First, the stigma of incarceration may depress the postprison earnings of dropouts, and eliminate any positive signaling value of the GED credential. Second, many dropouts who obtained a GED while incarcerated may have zero earnings five years later because they are still in prison. With the data used in this project, we have no way of sorting out the importance between these two complementary explanations for the difference between the signaling value of the GED for white and minority dropouts.

A second explanation for the minority results hinges on the following: (a) different behavioral assumptions behind why individuals acquire the credential, (b) different white-minority distributions associated with those behavioral assumptions, and (c) employers engaging in statistical discrimination when faced with lack of information. ${ }^{24}$ Under this explanation, one set of dropouts acquires a GED because they either place a value on the credential or they perceive that employers place a value on the credential. Another set of dropouts acquires the credential incidentally because it is "quasi-compulsory" in a program from which they are seeking benefits. Examples of such programs are Aid to Families with Dependent Children (AFDC), J ob Training Partnership Act (J TPA) programs, the J ob Corps, and many community level youth employment programs directed toward young dropouts.

The GED may be a signal of productive attributes for the group that actively pursues the signal and a signal of "government program participation" for those who acquired it in an incidental fashion. Employers may discount the value of the "incidental" GED relative to the "actively pursued" GED. If the distributions of "actively pursued" and incidental GED-holders differ by race/ ethnicity, then we would expect the signaling returns to the credential to differ across the white and minority groups.

Exploring this "government-program-GED" hypothesis is difficult, because the only estimates we can generate for adult dropouts come from information on J TPA classroom programs, while the only estimates for dropouts younger than 21 come from the relatively small yearly cohorts of the J ob Corps. There is no discussion. 
systematic data collection on the large numbers of dropout youths who received GEDs while in community-based, governmentfunded employment programs [Bos 1999].

Nevertheless, we can get somerough estimates of the percentages of GEDs that are obtained through government sponsored programs by white/minority status. To estimate GED numbers obtained through J TPA participation, we start with the fact that 146,952 individuals participated in J TPA classroom programs in 1990 [Committee on Ways and Means, U. S. House of Representatives 1993]. Next, we assume that white-minority proportions in the classroom component of J TPA programs are the same as overall JTPA proportions, 48 percent minority and 52 percent white. We next assume that for both whites and minorities, 42 percent of those in classroom programs obtained their GED in 1990. ${ }^{25}$ Based on these assumptions, we estimate that in 1990 about 29,600 minority and 32,000 white dropouts obtained their GED through J TPA participation.

Meanwhile, 70 percent of the participants in J ob Corps are minority group members. Again, we assume that 42 percent of the 49,200 new 1990 enrollees in the J ob Corps who were dropouts obtain their GEDs and that 70 percent of the newly minted GED-holders are minority and 30 percent are white. Based on these estimates, we estimate that an additional 14,500 minority dropouts obtained their GED while participating in J ob Corps activities, as compared with 6,200 white dropouts. Thus, we estimate that a total of 44,100 minority dropouts and 38,200 white dropouts obtained their GEDs through these two programs for which we can generate estimates.

Finally, we use weighted tabulations of the GED-holders in the NLSY to estimate that 73 percent of the 439,117 new GED credentials issued in 1990 [GED Testing Service 1991] went to white dropouts and 27 percent to minority dropouts. Based on these assumptions, 37 percent of the GEDs awarded to minority dropouts and 12 percent of the GEDs awarded to white dropouts in 1990 may have been associated with either J TPA classroom training or J ob Corps participation. If GEDs awarded through government-sponsored summer youth employment programs go disproportionately to young minority dropouts, then an even higher percentage of GEDs awarded to minorities could be

25. We base the 42 percent on GED attainment figures in the J OBSTART Demonstration [Cave et al. 1993]. At a 70 percent pass rate, this would mean that about 60 percent of program participants attempted the GED. 
through government program participation. These estimates of GEDs obtained through government-sponsored training at least go in the right direction and are potentially of sufficient magnitude to support the hypothesis outlined above. ${ }^{26}$

Support for this government-program-GED hypothesis based on evaluations of random assignment social experiments is mixed. Evaluations of the J OBSTART Demonstration, a J TPA-funded program directed at 17-21 year-old economically disadvantaged school dropouts, found that program participation increased GED receipt by a statistically significant $\mathbf{1 3 . 4}$ percent points [Cave et al. 1993]. However, the evaluation also indicated that the treatment group did not have subsequently higher earnings than the control group, a finding that fits with the government-programGED hypothesis.

\section{SUMmary AND CONCLUSIONS}

Using differential state GED passing standards as an identification strategy, we find that the signaling value of the GED increased the 1995 earnings of young white dropouts on the margin of passing the exams by 10 to 19 percent. We find no statistically significant evidence that the credential impacted the 1995 earnings of young minority dropouts in the same scoring range. Our results are robust across natural experiments that use different treatment and comparison groups. Finally, sensitivity analyses indicatethat possibleviolations of theidentifying assumptions used to obtain our estimates can explain little of those estimates.

At first glance, our results may appear inconsistent with Cameron and Heckman's [1993] finding of no statistical difference at age 25 between the average earnings of GED-holders and those of observationally similar uncredentialed dropouts. However, a closer look shows that the differences can be explained by differences in samples and methodologies. In particular, our estimates are based only on the lowest skilled GED-holders, those

26. We note that if employers can actually ascertain who did and did not obtain their GED on their own initiative, then the "real" value of the GED for whites would be $\$ 1500 /(1-0.12)=\$ 1705$, and that based on this we should get an estimate for minorities of $\$ 1705 \times 0.37=\$ 631$. While this estimate is within the confidence intervals of our estimates for minorities in Table $\mathrm{V}$, it is relatively far from the point estimates for minorities in that table. Wealso note, however, that if the "GED-in-prison" effect we discussed earlier is important in depressing the earnings of minority males, then we would expect a pooled (male and female) minority estimate to be well bel ow the $\$ 631$ estimate. 
on the margin of passing the exams. In contrast, Cameron and Heckman base their finding on a sample of dropouts varying in initial skill level, and they adopt the assumption that the impact of the GED on earnings is independent of initial skill level. If GED effects are concentrated among the least skilled and are negl igible for the more-skilled dropouts, then our results pointing to large GED effects for the dropouts on the margin of passing the exams are potentially consistent with those of Cameron and Heckman.

The findings of two recent papers support this explanation. Using data from the NLSY, Murnane, Willett, and Boudett [1999] fit models in which the effect of GED acquisition on subsequent earnings is allowed to vary across initial skill levels. They find that three years after obtaining the credential, the annual earnings of male GED-holders who left school with very low cognitive skill levels are about 10 percent higher than the earnings of low scoring uncredentialed dropouts. They find no effect of the GED on the earnings of dropouts who left school with stronger skills. Murnane, Willett, and Tyler [1999] report the same patterns in HSB data.

The findings of these papers support our primary estimates indicating substantial GED effects for low-skilled dropouts. These papers also show that if the effect of the GED is constrained to be independent of initial skill level (the assumption made by Cameron and Heckman [1993]), the average difference between the earnings of GED-holders and observationally similar permanent dropouts is small-a result of the negligible effect of the GED on the earnings of higher skilled dropouts.

In closing, we note that our estimates represent the private returns to the labor market signaling component of the GED. As a result, the findings in this paper potentially raise important social welfare questions. If the GED signal only serves to redistribute earnings, raising the earnings of dropouts who acquire a GED at the expense of dropouts who do not acquire the signal, then the gross social returns to the credential are zero, and the net social returns are negative (since there are costs associated with obtaining the signal). If the GED signal leads to better matches between dropouts and jobs, however, then the social returns can equal or outweigh the privatereturns [Stigl itz 1975]. We have no empirical method of determining whether or not employers use the GED to better match dropouts to jobs, and so the impact of the GED on total social welfare remains an open question.

If there is a job-matching component to the credential, 
however, then the social returns to the GED are dependent upon the passing standards. To see this, note that a standard either so low as to allow everyone to pass or so high as to allow no one to pass would provide no job-matching information. Furthermore, it could be that maximization of total social welfare requires statespecific passing standards, since the underlying distributions of the skills of dropouts and the demand for skills by employers may vary from state to state. Thus, the decentralized manner in which GED passing standards are currently established may approximate the regime under which total social welfare would be the greatest. Less clear, however, is whether the current set of state passing standards-where states as diverse as New York and I owa have the same GED passing standard-is the set that maximizes any social returns to a GED.

\section{DATA APPEndix}

\section{A. Data Sources}

As discussed in the text, the underlying individual-level data for this project come from four different sources: the state departments of education in Connecticut, Florida, and New York and the GED Testing Service (GEDTS). Data from the three state departments of education represent the universe of 1990 GED attempters who, as of 1995, had not reattempted the test battery.

The data from the GED Testing Service were originally collected by the GEDTS as part of an ongoing, several-year project to study responses to proposed new GED test items, and as a result of idiosyncratic administrative decisions, these data contain considerably fewer observations in every state than the number of test-takers indicated in GEDTS reports on the 1990 tests [GED Testing Service 1991]. Based upon our review of the processes that produced the GEDTS data, we have no compelling reason to believe that within-state sample selection bias is a problem with these data. Also, about 50 percent of the observations in the data forwarded to us had missing writing scores. Inquiries to programmers at GEDTS indicated that the writing scores were missing as a result of administrative record-keeping decisions at GEDTS. To retain observations and prevent sample selection bias that might otherwise occur if we eliminated records with missing writing scores, we used a quartic function of the four test scores available to predict the writing score, and we fit separate models for males and females, whites and minorities. 


\section{B. SSN Validation}

Table IV, in the body of the paper, shows that SSA programmers successfully matched and validated a high percentage of records. Except in the case of N ew York, which is explained above, matches were validated using SSA data on sex, race, and year of birth. A proposed match was assumed to be valid if the GED and SSA sex codes matched and the GED and SSA years of birth differed by no more than two years in absolute value and if the GED and SSA race codes did not disagree on white versus black designation.

\section{Social Security Earnings Coverageand Taxable Maximum \\ As detailed by Angrist:}

OASDI and HI (Medicare) are contributory programs in which covered workers pay a tax and report earnings to the SSA via employers or the Internal Revenue Service. The SSA keeps track of taxable earnings on the Summary Earnings Record (SER) . . . Under the Federal Insurance Contributions Act (FICA) of the Self-employment Contributions Act (SECA), earnings are taxed for Social Security purposes up to the Social Security Taxable maximum, and are therefore recorded on the SER only up to this maximum. The taxable maximum has been raised every year. By 1980, over 85 percent of covered male workers had earnings below the maximum. A separate and higher taxable maximum was instituted for $\mathrm{HI}$ in 1991. All taxable earnings, whether reported for the purposes of OASDI or $\mathrm{HI}$, and whether reported as part of a mandatory or voluntary coverage provision, should appear on the SER.

About 95 percent of all jobs in the United States were covered by the OASDI program as of 1991. Exceptions fall into five major categories: (1) Federal civilian employees hired before 1984, (2) railroad workers, (3) some employees of State and local governments already covered under a retirement system, (4) household and farm workers with low earnings, and (5) persons with no wage and salary earnings and very low earnings from self-empl oyment. Members of the uniformed services have been covered since 1956, and receive noncontributory wage credits to improve their insured status. Recent important changes include the 1983 coverage of most federal employees and employees of nonprofit organizations, $\mathrm{HI}$ coverage of many state and local employees in 1986, OASDI coverage of State and local employees without an employer retirement plan in 1990, and coverage of reserve soldiers in 1987 [Angrist 1997].

Taxable maximum values for the years 1991-1995 are

$$
\begin{aligned}
& 1991-\$ 53,400 \\
& 1992-\$ 55,500 \\
& 1993-\$ 57,600 \\
& 1994-\$ 60,600 \\
& 1995-\$ 61,200 .
\end{aligned}
$$


Given the generally low annual earnings of dropouts, we did not anticipate that earnings values top-coded at the taxable maximum would bea problem in our data, and this turned out to be the case. I n the GEDTS, Connecticut, and Florida data, ${ }^{27}$ the percent of young dropouts with any top-coded values are 0.1 percent, 0.2 percent, and 0.2 percent, respectively.

\section{G. SSA Confidentiality E dit}

The SSA confidentiality regulations that affected the data released to us censored cells that had fewer than threeindividuals or cells where the standard deviation of earnings was zero. This censoring masked the 1995 mean earnings in 164 of the 2138 total cells released to us on individuals who took the GED battery in 1990.

\section{Statistical Appendix}

To fit the models used to obtain the estimates in Table VIII, we must first assign a metric to the GED score groups displayed in Table $\mathrm{V}$. We have chosen to use the within-state average of the GED mean score in each score group as this metric.

Given this scaling of the GED score groups, the estimates in Table VIII are based upon regressions where we are interested in $y_{i c}$, the true earnings of the $i_{\text {th }}$ person in the $c_{\text {th }}$ cell in our data. However, as a result of the nature of the data released to us by the Social Security Administration, we only have a sample estimate of the mean earnings, $\mu_{\mathrm{c}}$ in the $c_{\mathrm{th}}$ cell. We assume that $\mathrm{y}_{\mathrm{ic}}=\mu_{\mathrm{c}}+\mathrm{w}_{\mathrm{ic}}$ where $\mathrm{w}_{\mathrm{ic}} \sim \mathrm{N}\left(0, \eta^{2}\right)$.

We would like to fit models in which the dependent variable is the cell population mean earnings $\mu_{c}$, and the explanatory variables of primary interest are associated with individuals who make up the $c_{\text {th }}$ cell.

We do not know the population cell mean earnings, $\mu_{c}$, but we possess the sample estimates for each cell, $\hat{\mu}_{c}$, provided by the Social Security Administration. Weassume that

$$
\hat{\mu}_{\mathrm{c}}=\mu_{\mathrm{c}}+\mathrm{u}_{\mathrm{c}} \quad \mathrm{u}_{\mathrm{c}} \sim \mathrm{N}\left(0, \xi^{2}\right) .
$$

In our estimation we must account for the fact that the $\mu_{c}$ 's are estimated with varying precision. 
We represent the models we want to fit as

$$
\mu_{\mathrm{c}}=\mathbf{x}_{\mathrm{c}} \boldsymbol{\delta}+v_{\mathrm{c}}
$$

where $\mathbf{x}$ is a vector of the independent variables and $\boldsymbol{\delta}$ is a vector of regression parameters to be estimated. However, because the $\mu_{c}$ are unknown, we must instead fit the foll owing model:

$$
\hat{\mu}_{\mathrm{c}}=\mathbf{x}_{\mathrm{c}} \boldsymbol{\delta}+\left(v_{\mathrm{c}}+\mathrm{u}_{\mathrm{c}}\right)=\mathbf{x}_{\mathrm{c}} \boldsymbol{\delta}+\epsilon_{\mathrm{c}} \text {. }
$$

Assuming that $\mathrm{u}$ and $v$ are independent, that $\mathrm{E}\left[\boldsymbol{v} \boldsymbol{v}^{\prime}\right]=\sigma^{2} \mathbf{I}$, and that

$$
E\left[u_{m} u_{n}\right]=\left\{\begin{array}{ll}
\omega_{c}^{2}, & m=n \\
0, & m \neq n
\end{array}, \quad \text { where } \omega_{c}^{2}=\frac{\eta_{c}^{2}}{n_{c}},\right.
$$

with $\mathrm{n}_{\mathrm{c}}$ the cell frequency in the $c_{\mathrm{th}}$ cell, we have

$$
E\left[\epsilon \epsilon^{\prime}\right]=\sigma^{2} \Omega=\sigma^{2}\left[\begin{array}{ccc}
\frac{\sigma^{2}+\omega_{1}^{2}}{\sigma^{2}} 0 & \cdots & 0 \\
& \ddots & \vdots \\
& & \frac{\sigma^{2}+\omega_{C}^{2}}{\sigma^{2}}
\end{array}\right],
$$

where $\mathrm{C}$ is the total number of cells.

Efficient estimation of $\delta$ in equation (A1) requires a consistent estimate of $\boldsymbol{\Omega}$, which, in turn, requires estimates of each $\omega_{\mathrm{c}}^{2}$ and of $\sigma^{2}$. Estimates of the $\omega_{c}^{2}$ are obtained by using the cell variances (supplied by the SSA) to estimate the $\eta_{c}^{2}$, in combination with the cell frequencies $n_{c}$ (also supplied by the SSA). Following Hanushek [1974], we use a two-step estimator for $\sigma^{2}$. We then use our estimate of $\boldsymbol{\Omega}$ to form a weighted least squares (WLS) fit of the model in equation (5).

BROWN UNIVERSITY

HARVARD UNIVERSITY

HARVARD UNIVERSITY

\section{REFERENCES}

Angrist, J oshua D., "Estimating the Labor Market Impact of Voluntary Military Service Using Social Security Data on Military Applicants," Econometrica, LXVI (1997), 249-288.

Arrow, Kenneth j.., "Higher Education as a Filter,"J ournal of Public E conomics, II (1973), 193-216.

Bos, Hans, Personal communication, April 1999. 
Boudett, Kathryn Parker, "In Search of a Second Chance: The Consequences of GED Certification, Education, and Training for Young Women without High School Diplomas,"'Ph.D. thesis, Harvard University, 1998.

Cameron, Stephen V., and J ames J. Heckman, "The Nonequivalence of High School Equivalents,"J ournal of Labor Economics, XI (1993), 1-47.

Cave, George, Hans Bos, Fred Doolittle, and Cyril Toussaint, j' OBSTART: Final Report on a Program for School Dropouts (Manpower Demonstration Research Corporation, 1993).

Committee on Ways and Means, U.S. House of Representatives, "Overview of Entitlement Programs: 1993 Green Book" (Washington, DC: U. S. Government Printing Office, 1993).

Erwin, Catherine, Personal communication, September 1999.

GED Testing Service, GED 1990 Statistical Report (Washington, DC: American Council on Education, 1991).

Hanushek, Eric A., "Efficient Estimators for Regressing Regression Coefficients," American Economic Review, LXIV (1974), 66-67.

J aeger, David, and Marianne Page, "Degrees Matter: New Evidence on Sheepskin Effects in the Returns to Education," University of Michigan, Population Studies Center, Research Report No. 94-307, 1994.

Kane, Thomas J., and Cecilia Rouse, "Labor Market Returns to Two-Year and Four-Year College," American E conomic Review, LXXXV (1995), 600-614.

Lang, Kevin, and David Kropp, "Human Capital versus Sorting: The Effects of Compulsory Attendance Laws," Quarterly J ournal of Economics, CI (1986), 609-624.

Lee, David S., "Wage Inequality in the United States during the 1980s: Rising Dispersion or Falling Minimum Wage?" Quarterly J ournal of Economics, CXIV (1999), 977-1024.

Murnane, Richard J ., J ohn B. Willett, and Katherine P. Boudett, “Does Acquisition of a GED Lead to More Training, Post-Secondary Education, and Military Service for School Dropouts?" Industrial and Labor Relations Review, LI (1997), 100-116.

Murnane, Richard J., J ohn B. Willett, and Katherine P. Boudett, "Do Male Dropouts Benefit from Obtaining a GED, Post-Secondary Education and Training?" Evaluation Review, XXIII (1999), 475-502.

Murnane, Richard J., J ohn B. Willett, and J ohn H. Tyler, "Who Benefits from Obtaining a GE'D: Evidence from High School and Beyond," Review of E conomics and Statistics, LXXXII (2000), 23-37.

Park, J in Heum, "E stimation of Sheepskin Effects and Returns to Schooling Using the Old and the New CPS Measures of Educational Attainment," Princeton University Industrial Relations Section Working Paper No. 338, August 1994.

Spence, Michael, "J ob Market Signaling," Quarterly J ournal of Economics, LXXXVII (1973), 355-374.

Stiglitz, J oseph, "The Theory of Screening, Education, and the Distribution of Income," American E conomic Review, LXVI (1975), 283-300. 